\title{
Research on the Development Predicament and Countermeasures of O2O E-commerce Model
}

\author{
- A Case Study of Suning Commerce \\ Wu Ye $\mathrm{e}^{1}$ \\ ${ }^{1}$ Shanghai University, Shanghai, 200444, China
}

Keyword: O2O model, Characteristics, Predicament, Countermeasures

\begin{abstract}
With the advent of the mobile Internet era, the gradual online and offline integration becomes common and $\mathrm{O} 2 \mathrm{O}$ model has become a general trend. Based on the author's work and learning experience, this paper analyzes the characteristics of Suning O2O model and then studies the existing problems, such as traffic driving, supply chain, customer relations and consumption experience. Finally this article puts forward corresponding countermeasures.
\end{abstract}

\section{Introduction}

O2O (Online to Offline) model refers to a new business model that living consumption is achieved by the interaction between online (virtual world) and offline activities (real world) in the mobile Internet. This specifically refers to that offline services use websites or mobile terminals to push services to the user and the user completes the online payment to receive services offline. That model combines offline business opportunities with the Internet together, so that the Internet becomes the front desk of offline transactions. It is observed that online and offline symbiotic integration is the core of $\mathrm{O} 2 \mathrm{O}$. O2O model has four dependence relations: Online to Offline, Offline to Online, Offline to Online to Offline, Online to Offline to Online. From the perspective of era development and consumption trend, $\mathrm{O} 2 \mathrm{O}$ model not only is in line with the consumers' changing needs, but also makes the business ready to meet customers' demand. Enterprises can have a positive interaction with customers through $\mathrm{O} 2 \mathrm{O}$ to get more profits. $\mathrm{O} 2 \mathrm{O}$ model has a more broad space for development and a higher commercial value, which is the future commercial operation pattern for the industry and academia and which is the development trend of the retail industry in the future.

\section{The Starting of Suning Commerce}

There are two main reasons why Suning is the first to do O2O reform in the same e-commerce companies. First, as an almost twenty-year old enterprise which grew from a traditional retailer, Suning gradually establishes the core value that is the service through endless exploration and reform. It also develops a strategic blueprint which is to improve logistics distribution system and information technology to enhance its core competitiveness. The accumulated customer group over these years and highly developed hardware conditions laid a good foundation for the development of double integration O2O model for Suning. Second, from 2009, Suning has prepared for O2O model and it has gone through expanding the category and business channels, removing electrification and putting Suning E-commerce online. This prepares fully for the double integration. 
To be first to develop O2O e-commerce model, Suning gains the initiative opportunity in the industry and achieves the dominant position in the future competition in the e-business. Suning $\mathrm{O} 2 \mathrm{O}$ model can be summarized as Shops +E-commerce+ Retailer. Its core is to integrate Suning front desk and background, combine the online and offline, serve the whole industry and service the entire customer group based on the cloud technology.

\section{Development Predicament of Suning O2O Model}

Traffic flow of Suning is unstable and driving traffic is enormously stressful. System performance of Suning website needs to be strengthened. It takes longer time to connect the homepage and there is too few option accounts of partner sites to log in Suning website. Moreover, this website is unable to withstand the pressure of promotional periods. Suning chooses O2O model and hopes to drive the online impulse type flow to the offline stores. Suning website is mainly responsible for driving traffic. The problem is that the traffic flow of Suning website itself is unstable and how is it to undertake the important task? According to rankings of international authoritative website ALEXA, the annual traffic flow of Suning website changes radically. In the promotion on Eleventh November and monthly promotion on Eighth every month (E18), its traffic rank is within 100 and it comes back to the 500 or so after these promotions. Obviously, the temporary promotions do not bring a stable customer group for Suning. We just go to the market in promotional period and our attention is far better than purchasing power. This can be verified by data. In the first half of 2013, Suning website achieved sales income of 10.6 billion, an increase of $101 \%$. Q2 received revenue of 6.1 billion, an increase of $81.74 \%$. The reason why revenue growth slows down is mainly that promotions in Q2 is significantly fewer than Q1.

Categories rapidly expand and the supply chain management is more difficult. The reason why Jingdong Mall has been able to do well in e-commerce is that it has an excellent supply chain and self logistics. Currently, Jingdong monopolizes the 3C field (Computer, Communication and Consumer Electronics), especially computers (desktop computers, tablets, laptops) and mobile phones with ten billion categories. Jingdong has a mass of loyal consumers through great collection and fast distribution network. With the help of this advantage, Jingdong constantly erodes traditional territory of Suning, Dangdang and others. Suning hopes to achieve rapid expansion of categories through an open platform strategy to compete with Jingdong. However, the category expansion increases the management difficulty and it is even related to the reconstruction of supply chain logistics system. For example, in the process of the shift from large household appliances to small household appliances and communication products distribution process, due to the lack of small items sorting center, the delivery time of many goods is more than three days or even longer. It has a wide gap between Suning and its competitors who deliver goods at the same day, the next day and even deliver three times within a day. Another example is that Suning expands from the large household appliances to books. The lack of sales makes the bargaining power is low and the procurement cost rises sharply. Financial report of Dangdang shows that because of the category expansion and promotion, gross margin falls from $25 \%$ to $10.5 \%$.

Categories rapidly expand and consumption experience is difficult to unify. Suning will face how to maintain a unified service standard with rapid expansion of product lines, introduction of different categories and especially its access to the unfamiliar territory, or the consumer can not feel the same consumption experience. It is even more difficult to unify the service standard with the third-party platform introducing a large number of commercial tenants, because this requires a lot of experience. Tmall of Taobao starts doing an open platform with rich categories and it has first mover advantage. It suffers a lot when it unifies user experience. Taobao was also considered to be 
a market of fakes and low grade goods. After Taobao establishes Tmall, enters the Consumer Protection Union and pays the cash deposit, the situation began to improve.

Competitors set a high threshold and offline cost surges. Currently, logistics of Jingdong Mall which deliver good on the same day or the next day has been totally exceeded by Tencent. The distribution speed of Yixun with three times a day sets a higher threshold for the industry. The latecomer Suning is forced to fight. To meet the requirements of high threshold in the industry, Suning expects that many stores can bring advantages for the distribution. However, the requirements of warehouse stores and distribution centers are so different. With expanding product lines and upgrading competiveness, the optimizing logistics strategy becomes a substantial increase of logistics facilities, which makes Suning more stressful. There is no doubt that online cost advantage will be offset by the high offline cost.

It ignores customer relation management and online user experience needs to be improved. In order to follow the trend, Suning website once made a high-profile strategic cooperation with Tianya Community, with which to enhance brand awareness. Suning established Suning Points Mall in Tianya Community and built a forum. But when the author browsed the forum, he finds that there are three successive complaint posts to Suning service from Twelfth to Fifth in July, 2013 and many people have browsed these posts. Until early on the morning of Sixteenth, there is no one to deal with these posts. It is a rascally behavior that Suning platform does not allow negative feedback. Anger and resentment is always to vent. If consumers cannot do it in Suning, they will find other platforms. Online forums, Microblog, Wechat and other social networks are important carriers of word-of-mouth E-commerce and other users' assessment on a product will be referenced by potential sellers. At present, the influence of social networks is growing in the long run and the reputation and image of Suning will be compromised inevitably if it still does so.

\section{Countermeasures of Suning}

To open the third-party platform and provide support services for $\mathbf{O 2 O}$. Users want a one-stop shopping which meets all their needs. If there is a single variety which does not require frequent purchase, it is difficult to form a continuous stickiness. Multiple vertical e-commerce only gets new users to maintain sales through continuous purchase of flow. This results in high market costs. Therefore, there is no other choice for Suning but to open the third-party platform. In addition to large household appliances, baby and mommy products, cosmetics and other core categories, Suning should open other categories as soon as possible. However, there are fewer opportunities to open an open platform. The reason is that Tmall, QQ Mall and other platforms have obvious plat roof advantage and has enough users and commercial tenants. The Matthew Effect will appear and it is easy for them to monopolize the market. Therefore, it will be a long arduous process to develop an open platform and expand the category in order to obtain more traffic flow and more user stickiness. The advantage of $\mathrm{O} 2 \mathrm{O}$ model is that products can be both displayed online and in physical stores. Suning can allow online stores on the platform to settle in Suning physical store to display products. This will reduce the sense of distance and increase the sense of reality. Stores unable to do online business can also display products on Suning electronic shelf stores, video and other forms to fully increase exposure. At the same time, Suning provides various ancillary services for commercial tenants with open platforms to solve their worries, such as IT services, warehousing and distribution services, microfinance and so on.

To carry out social network marketing and drive traffic flow for Suning. The report released by Monetate in August 2012, a marketing company shows that the traffic contribution of social networking to online shopping increases by $77 \%$ in one year. According to the monitoring data 
released by Hitwise in October, 2012, a third-party agency shows that $8.6 \%$ outgoing traffic of Microblog is to e-commerce and local information websites. Users will make a purchase decision based on friends or strangers' recommendation on social networks, which involves in online and offline purchases. Suning must pay attention to social networks and establish a specialized marketing team. They should take marketing campaigns, conduct public opinion monitoring and improve the customer relation to drive traffic flow for Suning by establishing its web space in popular social networks, such as Sina Microblog, WeChat, Tianya Community and Douban.

To optimize store layout and consolidate the advantages in third and fourth-tier cities. The staring data in Suning financial report of the second half year is that its offline revenue grows $11.03 \%$ compared to the store. It improves 0.9 percentage points compared with Q1. This revenue growth is related to large-scale closing shops in Q1, 2013. In the first half year, Suning opened 28 new stores in Chinese Mainland and closed 120 stores. While the number of stores is decreasing, its profitability is growing. Currently, the penetration rate of online shopping is higher in first and second-tier cities, but store sales is still the main shopping way in the third and fourth-tier cities. For example, the competiveness of Jingdong appliances is still very weak in the third and fourth-tier cities. Although Jingdong has established dozens of large warehouses in many places to improve distribution efficiency and reduce distribution costs, categories in large warehouses are often limited and there is a wide gap between products in warehouses and rich and personalized online products. This leaves precious time for Suning to optimize the store layout and consolidate advantages in third and fourth-tier cities.

\section{Conclusion}

In the era of development of big data, traditional companies have to use the power of the Internet to achieve the company's own transformation and tap new profitable point. $\mathrm{O} 2 \mathrm{O}$ is the best model for traditional enterprises to enter the e-commerce industry. But in the specific implementation process, different industries should take different measures to implement this business model according to their own characteristics. They also should improve innovation and realize the online and offline integration. It is not sustainable that the online and offline low prices of one product are the same. To sacrifice profit is certainly a short-term behavior. After all, compared to online stores, the cost of offline stores is much higher. If you should maintain the same price for a long term, you are bound to raise the terminal price, which is paid by consumers. Moreover, once O2O model is successful, the website will put pressure on upstream manufacturers by virtue of the user size and market position. To charge suppliers with high slotting allowance probably repeats itself. Therefore, Suning implementation of $\mathrm{O} 2 \mathrm{O}$ model cannot process very well, but there is not much time left to Suning. It should actively respond to the problems to be invincible in the future.

\section{References}

[1] Cao Yixia, Ni Shuyang. Suning: E-commerce: Leading O2O Revolution for E-commerce [J]. Shanghai Economy, 2014, Z1: 34-36.

[2] Zou Limin, Yan Yan, Luo Lisha. An Interpretation of Suning O2O Model [J]. Business Research, 2014, 13: 26-28.

[3] Zhao Guijun. The Application of O2O Model in the Retail Industry [J]. Chinese and Foreign Entrepreneurs, 2013, 27: 42-44.

[4] Cheng Yan, Tang Yu. O2O: Leading Diversified Retail Era [J]. Market Modernization, 2013, 31: $22-27+5$. 
[5] Cui Jing. The Pathfinder of O2O Model, Suning [J]. China Economy and Informatization, 2013, 02: 58-60. 